\title{
Treatment of domestic wastewater using upflow anaerobic sludge blanket reactor
}

\author{
${ }^{1}$ J. R. Banu; ${ }^{2}$ S. Kaliappan; ${ }^{1 *}$ I. T. Yeom \\ ${ }^{1}$ Civil and Environmental Engineering Centre for Zero Emission Technology Sung Kyun Kwan University, Korea \\ ${ }^{2}$ Centre for Environmental Studies (CES) Anna University, Chennai- 600025 Tamilnadu, India \\ Received 4 March 2006; revised 27 August 2006; accepted 5 April 2007; available online 20 June 2007
}

\begin{abstract}
This paper presents the findings of the study on treatment of domestic wastewater using a laboratory scale Hybrid Upflow Anaerobic Sludge Blanket (HUASB) reactor. The reactor with a working volume of $5.9 \mathrm{~L}$ and plastic cut rings as packing media was operated at varying Hydraulic Retention Time (HRT) for a period of 110 days. While the COD removal varied from 75-86\%, the BOD removal was in the range of $70-91 \%$. Methane content in the biogas was $62 \pm 3 \%$. VFA levels fluctuating between 100 and $186 \mathrm{mg} / \mathrm{L}$ (as acetate) did not pose operational problems such as souring of the reactor. During the treatment, nutrient levels exhibited an increasing trend. HUASB system could be designed with very short HRT of 3.3 hours, which will reduce the treatment cost significantly. It appears to be a promising alternative for the treatment of domestic wastewater in developing countries like India
\end{abstract}

Key words: $H U A S B$, domestic wastewater, biogas, treatment efficiency

\section{INTRODUCTION}

In developing countries like India where access to safe drinking water is not guaranteed for a majority of the population, it is of great importance to maintain the quality of surface water sources. Chennai, one of the four-mega cities in India is the best example for pollution of surface water bodies caused by discharge from sewer outfalls. For instance, Central Pollution Control Board (CPCB) and Ministry of Environment and Forests (MoEF) (2001) have reported that Adyar and Coovum rivers passing through the city receive wastewaters from 141 and 276 sewer outfalls, respectively. At present, there are 6 Sewage Treatment Plants in Chennai with an overall treatment capacity of 267 MLD. It is estimated that the domestic wastewater generation in Chennai would be of the order of 800 MLD by the year 2021 (CPCB and MoEF, 2001). This scenario warrants an urgent need to develop technologies to treat huge volumes of wastewaters in shortest possible time frame. Advances in anaerobic treatment of domestic wastewater offer a few promising options including Upflow Anaerobic Sludge Blanket (UASB Heertjes and Van der Meer, 1978; Lettinga and Vinken, 1980; Lettinga, et al., 1980), Anaerobic Filter (AF Chernicharo and Machado, 1998; Bodik, et al., 2000),

\footnotetext{
\*Corresponding Author Email: yeom@skku.ac.kr
}

Tel.: 8231299 3092; Fax: 82312996658
Expanded Granular Sludge Bed (EGSB - Van der Last and Lettinga, 1992; Seghezzo, 1997), Anaerobic Baffled Reactor (ABR- Langenhoff and Stuckey, 2000 and Bodik, et al., 2003), Hybrid reactor (HR - Elmitwalli, et al., 2002a and 2002b) and Anaerobic Migrating Blanket Reactor (AMBR - Angenent and Sung, 2001). It is reported that most of the negative aspects of high rate anaerobic reactors can be overcome by restricting the supported material to the top 25 to $30 \%$ of the reactor volume (Guiot and Van den berg, 1984; 1985). This would help realize the advantages of both fixed film and up flow sludge blanket treatment. This kind of reactor is called Hybrid Upflow Anaerobic Sludge Blanket (HUASB) and is considered more stable for the treatment of a series of soluble or partially soluble wastewaters (Tilche and Vieira, 1991). Over the years, HUASBs have been used to treat a variety of industrial effluents (Coates and Colleran, 1990; Rajesh, et al., 2006 a,b; Shivayogimath and Ramanujam, 1999). In the present study, HUASB has been used to treat domestic wastewater.

\section{MATERIALS AND METHODS}

The laboratory scale HUASB reactor was fabricated using PVC tube with an internal diameter of $11 \mathrm{~cm}$ and an overall height of $88 \mathrm{~cm}$ (Fig. 1). The working volume 
of the reactor was 5.9 L. A gas headspace of $1.5 \mathrm{~L}$ was maintained above the effluent line. A screen was placed at a height of $60 \mathrm{~cm}$ to arrest the floating carrier material - plastic cut rings. One hundred and fifty plastic cut rings were used as carrier material. A peristaltic pump (Make: Miclins, Model: PP 20) was used for feeding wastewater into the reactor. The effluent pipeline in turn was connected to a water seal to prevent the escape of gas. The gas outlet was connected to a wet gas meter (Make: Ritter, Model: TG05).

\section{Wastewater}

The domestic wastewater used for the present study was collected from Nessapakkam STP (Sewage Treatment Plant), Chennai, India.

\section{Acclimatization}

"Start-up" phase of the reactor during the study was not warranted, as the HUASB used was a granulated one. To acclimatize the methanogens to the new substrate, the reactor was operated for a period of 30 days at a HRT of 7.4 hours with domestic wastewater.

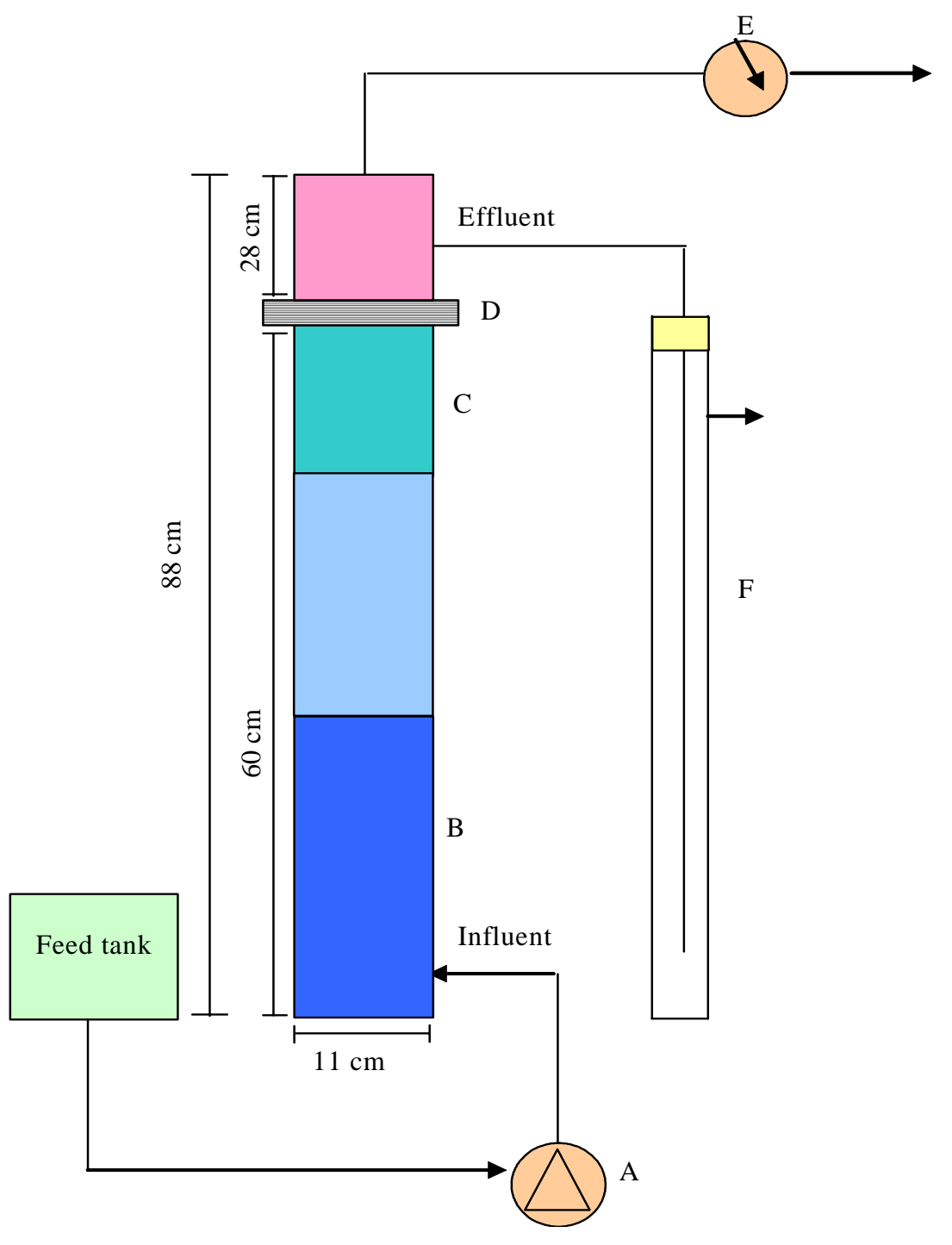

A - Peristaltic pump B- Sludge bed C- Floating filter (PVC Cut rings)

D - Screen E - Wet gas meter F - Water seal

Fig. 1: Schematic diagram of the HUASB with PVC cut rings 
Operational Condition during the study

The initial HRT was $7.3 \mathrm{~h}$ and it was gradually decreased to $3.3 \mathrm{~h}$ over a period of 110 days. This was achieved by increasing the flow rate from $800 \mathrm{~mL} / \mathrm{h}$ to $1800 \mathrm{~mL} / \mathrm{h}$.

\section{Chemical analysis}

Chemical Oxygen Demand(COD), Volatile FattyAcids (VFA), Alkalinity, Total Solids (TS), Volatile solids (VS) and Total Kjeldhal Nitrogen (TKN) of the raw and treated wastewater were analysed following Standard Methods (1998).Phosphate $\left(\mathrm{PO}_{4}^{3-}\right)$, sulphate $\left(\mathrm{SO}_{4}{ }^{2-}\right)$ and chloride $\left(\mathrm{Cl}^{-}\right)$were analyzed employing ion exchange chromatography (Make: Dionex, Model: DX-120) after filtering the samples through a $0.45 \mu \mathrm{m}$ filter. The eluent was a combination of $3.5 \mathrm{mM}$ bicarbonate and $1 \mathrm{mM}$ carbonate; the flow rate was $1.2 \mathrm{~mL} / \mathrm{min}$ with an injection volume of $25 \mu \mathrm{L}$. Methane content in the biogas was measured by Gas Chromatography (Make: Chemito, Model: GC 1000) equipped with Flame Ionization Detector (FID). The column used was Proapak Q.

\section{RESULTS}

Fig. 2 illustrates the influence of Hydraulic retention time (HRT) on $\mathrm{pH}$ and biogas production. The $\mathrm{pH}$ of the treated wastewater was in the range of $7.4-8.1$, which is indicative of satisfactory condition of the reactor. It is known that $\mathrm{pH}$ value less than 6.8 and greater than 8.3 would cause souring of reactor during anaerobic digestion (Stronach et al 1986; Wheatly, 1991). The biogas production was in the range of 1800 to $7080 \mathrm{~mL} /$ day. Gas production rates were highly variable due to the fluctuation of organic concentration in the influent. Maximum gas production (7080 mL/day) was recorded at a HRT of 3.3 h. The present values are relatively higher than those reported by earlier workers (Kobayashi, et al., 1982; Ligero and Soto, 2002). Higher volumes of biogas recorded during the present study can be attributed to higher concentrations of organic matter present in the wastewater. Methane content in the biogas was $62 \pm 3 \%$. This value is comparable to $59 \pm 3.2 \%$ reported for gas produced during the treatment of domestic wastewater using anaerobic hybrid reactor (Elmitwalli, et al., 2002a). In contrast to the present observations, Kobayashi et al. (1982) has reported very high methane content of $92 \%$ for biogas produced during the treatment of domestic wastewater using anaerobic filter. It is known that gas generated during treatment using anaerobic filter generally has higher methane content as compared to any hybrid reactor (Elmitwalli, 2002b). Fig. 3 depicts the influence of HRT on alkalinity and volatile fatly acids (VFA) accumulation in the wastewater during the treatment. Alkalinity of the medium increased from $610 \mathrm{mg} / \mathrm{L}$ at a HRT of $7.3 \mathrm{~h}$ to 744 $\mathrm{mg} / \mathrm{L}$ at a HRT of $3.3 \mathrm{~h}$. The alkalinity in the medium was stabilized during the last three operational phases. At different phases, the VFA as acetate in the medium varied from 100 to $165 \mathrm{mg} / \mathrm{L}$. Low VFA levels in anaerobically treated domestic wastewater have been reported by several workers (Kobayashi, et al., 1982; Ligero and Soto, 2002; Elmitwalli, et al., 2002a). VFA has been recognized as one of the important intermediates during the anaerobic digestion (Ahring and Angelidaki, 1997; Wang, et al., 1999) and is considered a central parameter for anaerobic treatment (Ahring and Angelidaki, 1995; Pind, et al., 1999; 2002). Fig. 4 presents the data on COD removal during different phases of operation. COD removal rate varied from 76 to $86 \%$. Beyond a HRT $3.9 \mathrm{~h}$ marginal decrease in COD removal was noticed and the rate varied from 75 to $79 \%$ up to a HRT of $3.3 \mathrm{~h}$. The concentration of organics as COD in the raw domestic wastewater varied from $700-1368 \mathrm{mg} / \mathrm{L}$ and in the treated wastewater it was in the range of $140-295 \mathrm{mg} / \mathrm{L}$. As can be seen from Fig. 5 the BOD removal rate was between 70 and $92 \%$. This is comparable to 76-88 \% BOD removal reported during the treatment of domestic wastewater at a HRT of 4 and $6 \mathrm{~h}$ by Chernicharo and Machado (1998). While the BOD of the influent wastewater varied from $434-721 \mathrm{mg} / \mathrm{L}$ that of the treated wastewater was in the range of 47 - $175 \mathrm{mg} / \mathrm{L}$. Increase in HRT beyond $4.5 \mathrm{~h}$ caused a gradual decrease in BOD removal. The least BOD removal of $70 \%$ was recorded when the HRT was 3.3 h. Fig. 6 depicts the influence of OLR on the removal of TS and VS from the wastewater during the study. Removal of TS varied from 30 to $35 \%$ during most of the operational period; the removal was slightly less (28 $29 \%$ ) during the final two HRTs namely $3.5 \mathrm{~h}$ to $3.3 \mathrm{~h}$. This may be attributed to the increase in flow rate that applied in the final two HRTs. Removal of VS varied from 48 to $56 \%$ and as in the case of TS, at higher HRTs the removal efficiency decreased. Determination of VS is useful in the control of wastewater treatment plant operation because it offers rough approximation of the amount of organic matter present in the solid fraction of wastewater (Standard Methods, 1998). Table 1 presents the characteristics of raw and treated domestic wastewater during the treatment. It is evident from the table that the levels of nitrogen, phosphorus and 
potassium in the treated wastewater were higher than in raw wastewater. Increase in nutrient levels during the anaerobic treatment of wastewater is a common occurrence and is attributed to the mineralization of organic compounds (Hanndel and Lettinga, 1994). This nutrient rich treated wastewater needs further treatment, as nitrogen and phosphorus cause algal blooms in receiving water bodies. Ammonia concentration in the wastewater during all the phases of operation increased as a result of ammonification. The removal of sulphate from the wastewater during the treatment was significant. The chloride concentration in the effluent remained unaffected during the treatment.

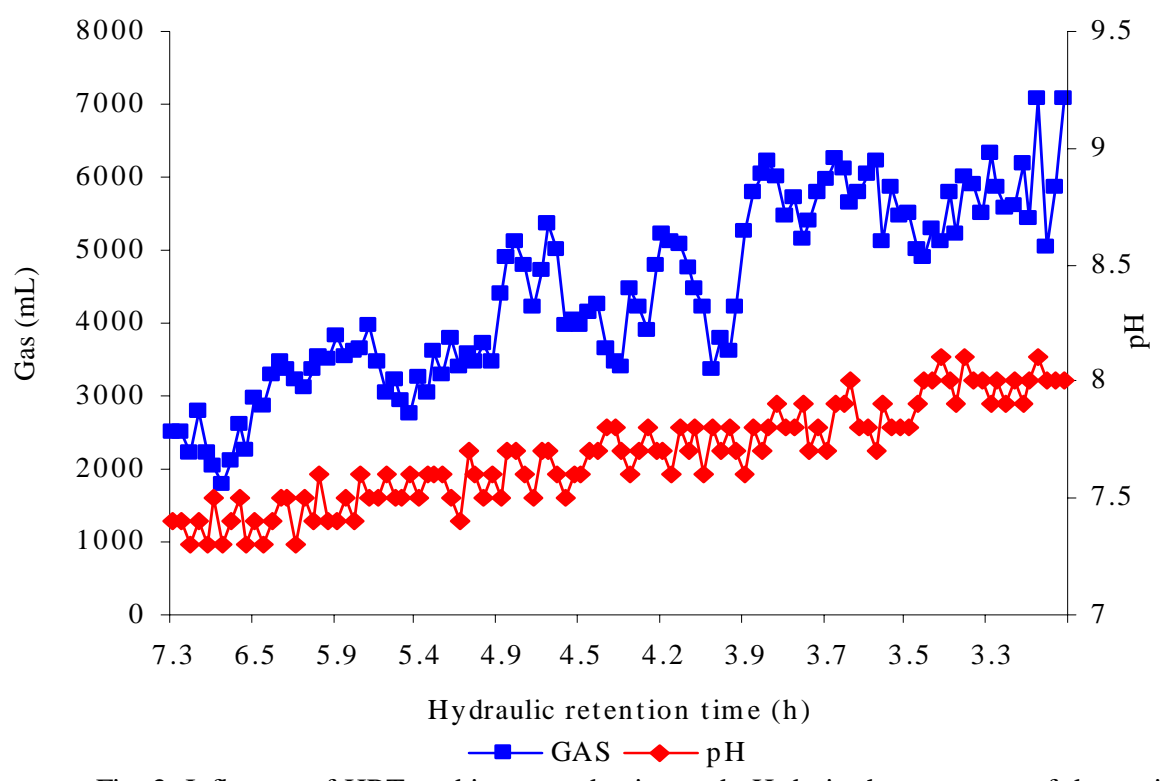

Fig. 2: Influence of HRT on biogas production and $\mathrm{pH}$ durin the treatment of domestic wastewater using HUASB with PVC

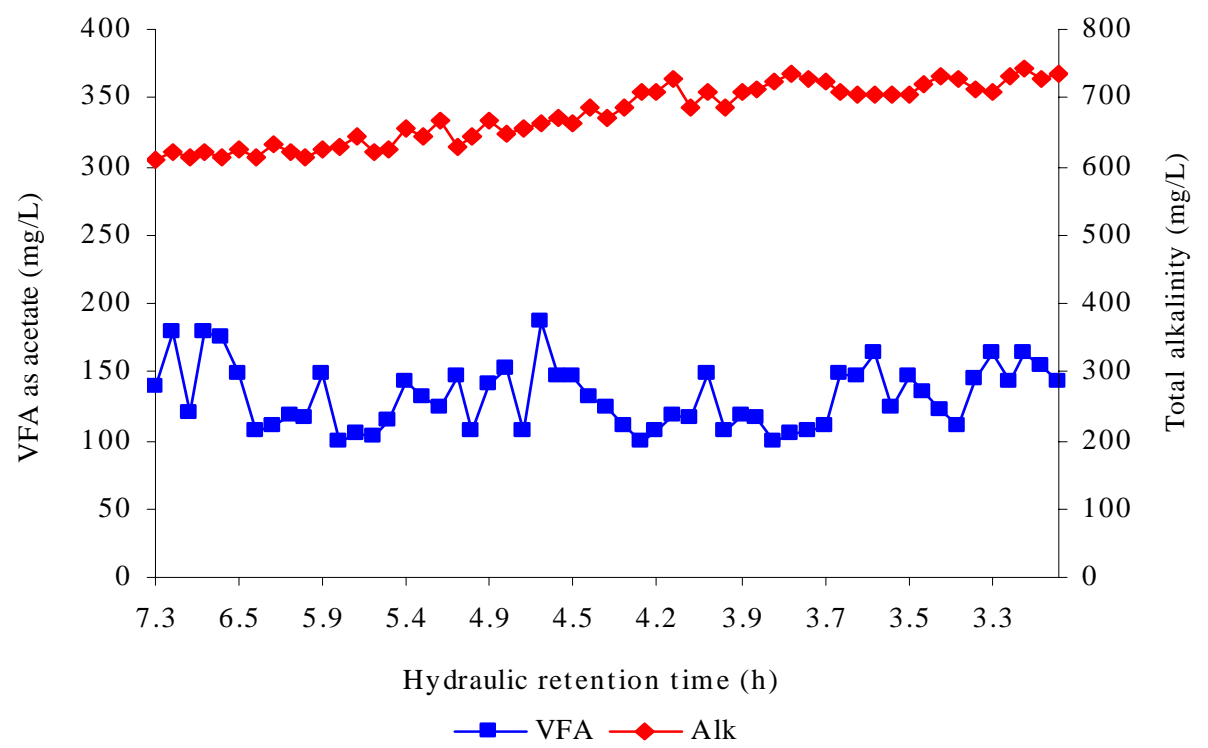

Fig. 3: Influence of HRT on VFA and alkalinity during the treatment of domestic wastewater using HUASB with PVC 


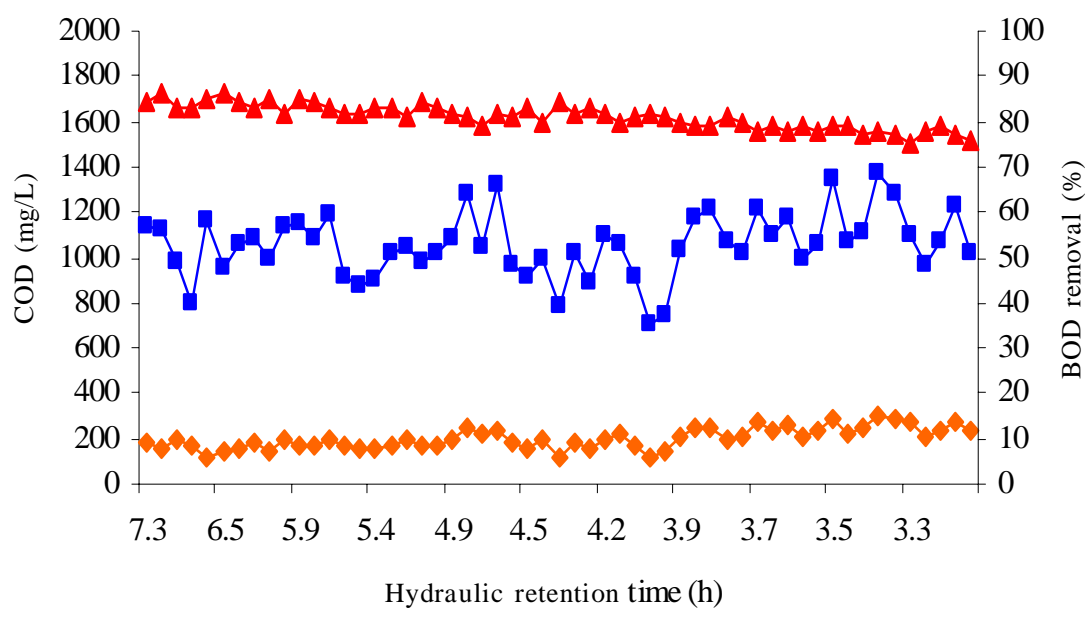

$\neg-$ COD inf. $\prec$ COD eff. $\multimap$ COD removal (\%)

Fig. 4: influence of HRT on COD removal during the treatment of domestic wastewater using HUASB with PVC

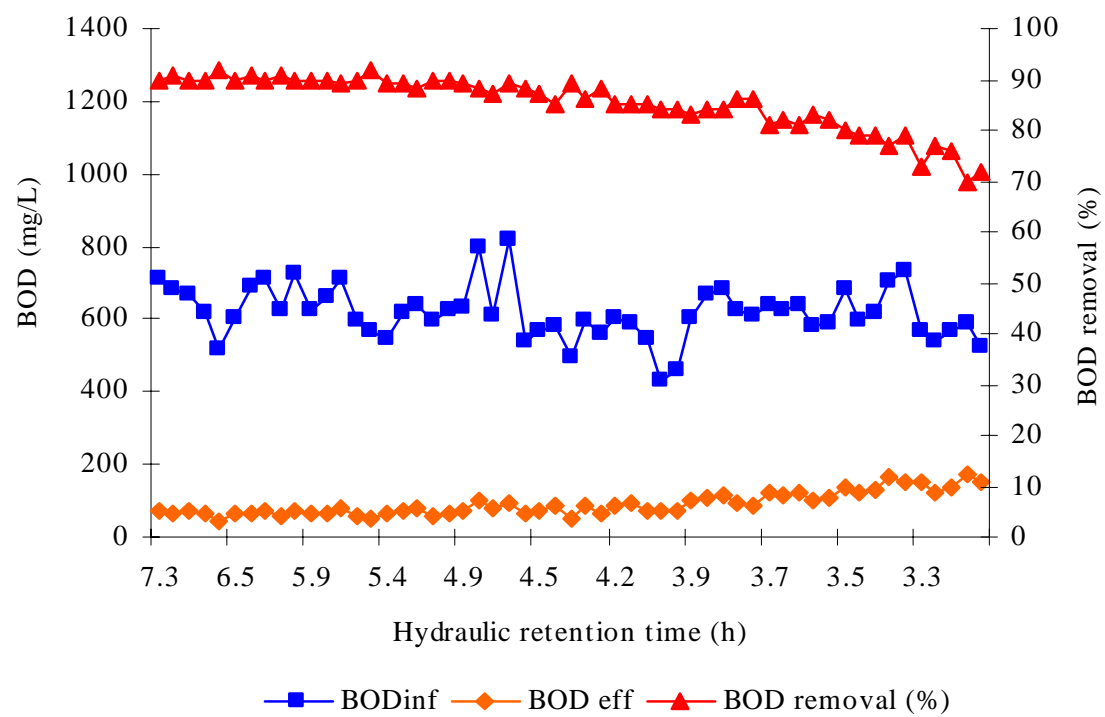

Fig. 5: influence of HRT on BOD removal during the treatment of domestic wastewater using HUASB with PVC

\section{DISCUSSION AND CONCLUSION}

Anaerobic treatment of domestic wastewater employing HUASB efficiently removed organics both COD and BOD with in very short period of time. Comparatively lower organics removal efficiencies during the treatment of domestic wastewaters using UASB at different HRTs have been reported by several workers (65\% at a HRT of $4 \mathrm{~h}$ - Haskoning, 1989; 53\% at a HRT of $4.4 \mathrm{~h}$ - Viera and Garcia, 1991; 72\% at a HRT of $5 \mathrm{~h}$ - Schellinkhout and Callazos, 1991). The commonly encountered problem of VFA induced 'souring' of the reactor was not encountered during the present study as the VFA levels were quite low. Interestingly, the 


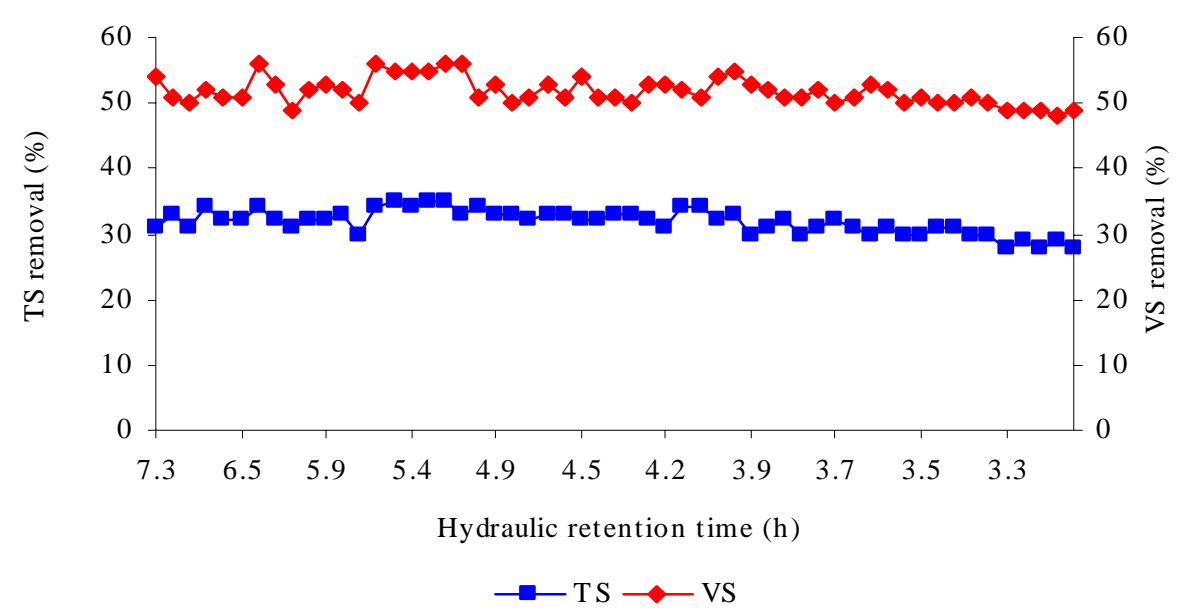

Fig. 6: Influence of HRT on TS and VS removal during the treatment of domestic wastewater using HUASB with PVC

Table 1: Influent and effluent characteristics during treatment of domestic wastewater using HUASB with PVC

\begin{tabular}{lll}
\hline Parameter & $\begin{array}{l}\text { Concentration } \\
\text { influent (mg/L) }\end{array}$ & Effluent \\
\hline TKN & $43.4-49.0$ & $47-53.2$ \\
NH3-N & $23-28.5$ & $42-48.1$ \\
Chloride & $160-188$ & $160-188$ \\
Sulphate & $39-56$ & $15-24$ \\
Phosphate & $14.8-16.6$ & $16.2-19.1$ \\
Potassium & $13.5-17.1$ & $14.1-18$ \\
\hline
\end{tabular}

alkalinity in the medium was also low indicating the fact that buffering effect of alkalinity was not warranted. In a critique on the functioning of anaerobic reactors Hanndel and Lettinga (1994) have also opined that VFA accumulation does not "sour" the reactor during the treatment of domestic wastewater and $\mathrm{pH}$ correction therefore is not essential. The reduction in COD and BOD removal efficiency at higher HRT may be attributed to higher upflow velocity of the wastewater and the consequent reduction in contact time between organics in the wastewater and microbes. Results obtained in the present study demonstrate that HUASB with PVC can promote enhanced COD and BOD removal from domestic wastewater. HUASB system can be effectively used for the treatment of domestic waste in developing countries like India, since the system can be designed with relatively short HRT. Further, the biogas generated during the process adds attraction as it can be used as a fuel. Similarly, studies on starvation and shock loading would help evaluate the process and its application, paving way for pilot plant experiments. Work on these aspects is in progress.

\section{ACKNOWLEDGEMENT}

Authors were grateful to professor Diter Beck, senior advisor Indo-German project at Centre for Environmental Studies for his valuable suggestion and guidance during the research project.

\section{REFERENCES}

Ahring, B.K.; Angelidaki, I., (1995). Volatile fatty acids as indicators of process imbalance in anaerobic digestion. Appl. Microbiol. Biotechnol., 43, 559-565.

Ahring, B.K.; Angelidaki, I., (1991). Monitoring and controlling the biogas process. Proceeding at $8^{\text {th. }}$ international conference on anaerobic digestion. Sendai, Japan, 40-45.

Angenent, L.T.; Sung, S., (2001). Development of anaerobic migrating blanket reactor (AMBR), A novel anaerobic treatment system. Wat. Res. 35, 1739-1747. 
Bodik, I.; Kratochvil, K.; Gaspirkova.; Hutnan, M., (2003). Nitrogen removal in an anaerobic baffled filter reactor with aerobic post treatment. Biores. Technol., 86, 79-82.

Bodik, L.; Herdova, B.; Kratochvil, K., (2000). The application of anaerobic filter for municipal wastewater treatment. Proceedings of the $20^{\text {th. }}$ international conference of the Slovak society of chemical engineering, 54(3), 159-164.

CPCB and MoEF. (2001). Environmental improvement of waterways in Chennai-Report. Ministry of Environment and Forest, India.

Chernicharo, C.A.L.; Machado, R.M.G., (1998). Feasibility of UASB/AF system for domestic sewage treatment in developing countries. Wat. Sci. Tech., 38, 325-333.

Coates, J.; Colleran, E., (1990). Effect of initial agitation on the start up and operational performance of anaerobic hybrid reactors treating a synthetic feed. Process Biochem., 10, 162-171.

Elmitwalli, T.A.; Sklyar, V.; Zeeman, G.; Lettinga, G., (2000a). Low temperature pretreatment of domestic sewage in an anaerobic hybrid or an anaerobic filter reactor. Biores. Technol., 52, 233-239.

Elmitwalli, T.A.; Kim L.T.; Oahan Zeeman, G.; Lettinga, G., (2002b). Treatment of domestic sewage in a tow step anaerobic filter/anaerobic hybrid system at low temperature. Wat Res., 36, 2225-2232.

Guiot, S.R.; Van den Berg, L., (1984). Dynamic performance of an anaerobic reactor combining an upflow sludge blanket and a filter for the treatment of sugar waste. Proceedings of the 39th annual Purdue Industrial Waste Conference. Lafayette, 705-717.

Guiot, S.R.; Van den Berg, L., (1985). Performance of an upflow anaerobic reactor combining a sludge blanket and a filter treating sugar waste. Biotechnol and Bioeng., 27, 800806.

Hanndel, V.C.A.; Lettinga, G., (1994). Anaerobic sewage treatment- a practical guide for regions with a hot climate. Willey publisher, England.

Haskoning. (1989). Anaerobic treatment of domestic wastewater under tropical conditions - Final report. Royal Dutch Consulting Engineers and Architects.

Heertjes, P.M.; Van der Meer, R.R., (1978). Dynamics of liquid flow in an upflow reactor used for anaerobic treatment of wastewater. Biotechnol. Bioeng., 20, 1577-1594.

Kobayashi, H.A.; Stenstrom, M.K.; Mah, R.A., (1982). Treatment of low strength wastewater using the anaerobic filter. Water Res., 17(18), 903-909.

Langenhoff, A.M.; Stucky, D.C., (2000). Treatment of dilute wastewater using an anaerobic baffled reactor: Effect of low temperature. Water Res., 34(15), 3867-3875.

Lettinga, G.; Vinken, J.N., (1980). Feasibility of the upflow anaerobic sludge blanket (UASB) process for the treatment of low strength water. Proceedings of the 35th Purdue industrial waste conference. 625-634.

Lettinga, G.; Van Nelsen, A.F.H.; Hobma, S.W.; De Zeeu, W.W.; Klapwijk, A., (1980). Use of the upflow sludge (USB) reactor concept for biological wastewater treatment, especially for anaerobic treatment. Biotech. Bioeng., 25, 1701-1723.

Ligero, P.; Soto, M., (2002). Sludge granulation during anaerobic treatment of pre-hydrolyzed domestic wastewater. Water SA., 28 (3), 307-311.

Pind, P.F.; Angelidaki, I.; Ahring, B.K., (2002). Dynamics of the anaerobic process: Effects of volatile fatty acids. Biotech. Bioeng., 82(7), 791-801.

Pind, P.F.; Angelidaki, I.; Ahring, B.K., (1999). The use of VFA measurement as process indicators in anaerobic reactors treating manure. Proceedings of the II international symposium on anaerobic digestion of solid waste. Barcelona, 41-44.

Rajesh banu, J., Kaliappan, S. and Diter Beck. (2006a) Treatment of sago wastewater in hybrid anaerobic reactor. Water Qual. Res. J. Canada., 41, 56-62.

Rajesh banu, J.; Kaliappan, S.; Diter Beck. (2006b). High rate anaerobic treatment of Sago wastewater using HUASB with PUF as carrier. Int. J. Environ. Sci. Tech., 3(1), 73-81.

Schellinkhout, A.; Collazos, C.J., (1991). Full scale application of the UASB technology for sewage treatment. Proceedings of the 6th International IAWPRC symposium. Sao Saulo, Brazil.

Seghezzo, L. (1997). Kinetics and structure of anaerobic granular sludge from EGSB reactors. M.Sc thesis. Wageningen Agricultural University, Wageningen, The Netherlands.

Shivayogimath, C.B.; Ramanujam, T.K., (1999). Treatment of distillery spent wash by hybrid UASB reactor. Bioprocess Engineering. 21, 255-259.

Standard Methods. (1998). Standard Methods for the Examination of Water and Wastewaters. APHA, Washington D.C.

Stronach, S.M.; Rudd, T.; Lester, J.N., (1986). Anaerobic digestion process in the industrial wastewater treatment. Springer-Verlag, Berlin, Germany.

Tilche, A.; Vieira, S.M.M., (1991). Discussion report on reactor design of anaerobic filters and sludge bed reactors. Water Sci. Tech., 24, 193-206.

Van der Last, A.R.M.; Lettinga, G., (1992). Anaerobic treatment of domestic sewage under moderate climatic (Dutch) conditions using upflow reactors at increased superficial velocities. Water Sci. Tech., 25, 167-178.

Viera, S.M.M.; Garcia, A.D., (1991). Sewage treatment by UASB reactor, operation results and recommendations for design and utilization. Presented at the $6^{\text {th. }}$ International IAWPRC Symposium. Sao Paulo, Brazil.

Wang, Q.H.; Kuninobu, M.; Ogawa H.I; Kato, Y., (1999). Degradation of volatile fatty acids in highly efficient anaerobic digestion. Biomass Bioenergy., 16, 407-416.

Wheatley, A., (1991). Anaerobic digestion: A waste treatment technology. Elsevier Science publishers Ltd, U.K. 
J. R. Banu, et al.

\section{AUTHOR (S) BIOSKETCHES}

Banu, J. R., Ph.D., is a teaching post doctoral fellow in the Department of Civil and Environmental Engineering, SungKyunKwan University, Suwon-Si, Korea. Email: rajeshces@gmail.com

Kaliappan, S., B.E, M.E. PhD is a professor and Director of Institute of Remote Sensing, Anna University, Chennai, India. Email: drkalsun@yahoomail.com

Yeom, I.T., is a professor in Civil and Environmental Engineering and Director of Centre for Zero Emission Technology, SungKyunKwan University, Suwon-Si, Korea. Email: yeom@skku.ac.kr

This article should be referenced as follows:

Banu, J.R.; Kaliappan, S.; Yeom, I.T., (2007). Treatment of domestic wastewater using upflow anaerobic sludge blanket reactor. Int. J. Environ. Sci. Tech., 4 (3), 363-370. 